\title{
НЕВРОЛОГИЧЕСКИЕ АСПЕКТЫ ДИАГНОСТИКИ “ОФИСНОГО СИНДРОМА”: ОБЗОР ЛИТЕРАТУРЫ И СОБСТВЕННЫЕ НАБЛЮДЕНИЯ
}

\section{Савицкая И. Б.}

\section{ВВЕДЕНИЕ}

Человек трудоспособного возраста проводит на работе в условиях офиса в среднем 8 часов. Высокие информационные технологии, малоподвижный образ жизни, большое скопление людей, организация "open spase", ненормированный рабочий график, стрессы, неправильное и нерегулярное питание, концентрированное количество аллергенов, воздействующих на офисного служащего на протяжении 8 часов или $44,4 \%$ светового рабочего дня. Все это заставляет обратить внимание врачей различных специальностей на проблему клинических синдромов у работников с офисным режимом работы, в современной литературе сформулированное как “офисный синдром". Офисный синдром, по данным А.Б. Данилова, Ю.М. Курганова ${ }^{1}$ включает:

1. Мышечно-скелетные боли в спине, шее, верхних конечностях.

2. Цефалгии.

3. Синдром “компьютерной мыши” (туннельный синдром).

4. Сердечно-сосудистые заболевания (атеросклероз, гипертоническая болезнь, аритмия).

5. Синдром “сухого глаза".

6. Заболевания желудочно-кишечного тракта (гастрит, язва желудка и 12-перстной кишки, хронический колит).

7. Заболевания дыхательной системы: бронхиальная астма, бронхит, пневмония, простудные заболевания.

8. Геморрой и трещины прямой кишки, хронические воспалительные заболевания органов малого таза (хронический простатит у мужчин, хронический эндометрит, сальпингоофорит у женщин).

9. Ожирение.

10. Варикозное расширение вен нижних конечностей, тромбофлебит.

1 Данилов А.Б., Курганова Ю.М. Офисный синдром. Медицина неотложных состояний. 2012. № 7-8 (46-47) С. 167-173. 
Психосоциальная рабочая среда является важной частью эргономической оценки рабочего места. В процессе исследования проблемы "офисного синдрома" очень важно, чтобы работники имели возможность объяснить и описать свою рабочую среду и выявить проблемы и особенности психосоциальной ситуации, влияющих на них. Все больше доказательств того, что подверженность неблагоприятным организационным характеристикам работы, таким как высокие требования к производительности, в сочетании с низким уровнем контроля за работой и низкой социальной поддержкой на рабочем месте, люди подвергаются повышенному риску стресса и болезни 2 .

В литературе по гигиене труда появляется все больше доказательств того, что психосоциальные факторы труда влияют на развитие скелетно-мышечных проблем, включая нижнюю часть спины и плечевой пояс ${ }^{3}$.

Наиболее значимым патогенным воздействием рабочей среды является воздействие компьютера как неотъемлемой части офисной работы. V. Prodanovsa-Stocavska и соавт. провели обследование 800 офисных работников в возрасте $42 \pm 10,72$ года, чья ежедневная работа обязательно включала компьютер (не менее часа в день): $48 \%$ работников имели боль в области шеи и верхней части спины, $42 \%$ - в области поясницы, 5\% в локтевой области. Результаты исследования показывают потенциальный риск взаимосвязи между осанкой и появлением патологии костно-мышечной системы.

Автор обращает внимание, что наиболее пострадавшими являются те, кто поддерживает однообразную статичную позу с наклоненной вперед головой. Психосоциальные факторы труда определяются также как аспекты рабочей среды (такие как рабочие роли, работа под давлением и взаимоотношения на работе), которые могут способствовать переживанию стресса среди людей.

Анализ результатов психосоциальной анкеты с участием 800 офисных работников показал, что наибольшее количество респондентов никогда не откладывали свою работу, часто работали в высоком темпе и чувствовали эмоциональный стресс, на них иногда влиял объем работы, которую нужно было выполнить, а иногда была возможность влиять на новые проекты. Они чувствовали, что иногда

${ }^{2}$ Karasek R., Theorell T. Healthy Work. Stress, Productivity and the Reconstruction of Working Life. Basic Books Inc. Publishers, New-York. 1990. 756 p.

${ }^{3}$ Bongers P., Kremer. Are psychosocial factors, risk factors for symptoms and signs of the shoulder, elbow, or hand / wrist? : a review of the epidemiological literature. American Journal of Industrial Medicine. 2002. № 41. P. 315-342. 
могут проявить инициативу, часто считая, что их работа важна и имеет четко определенные цели. Кроме того, они отмечали, что иногда получают поддержку и помощь от своего наставника-менеджера, но при этом отмечали, что работа их истощает и в большой степени негативно сказывается на их личной жизни ${ }^{4}$.

\section{1. Коморбидность офисного синдрома}

Сочетание хронического болевого синдрома с психосоциальными проблемами ведет к наличию стресса, который оказывает уже не защитную, адаптационную роль, а оказывает повреждающее воздействие на многие органы и системы, формируя коморбидную основу “офисного синдрома".

Особого внимания заслуживает взаимоотношение ожирения, мышечно-скелетных болей и головных болей у офисных работников. Понимание сущности офисного синдрома лежит в анализе причины и природы его высокой коморбидности с целым рядом состояний: синдромом эмоционального выгорания, депрессией, тревожными состояниями, нарушениями сна, нервной булимией, хроническими алгическими синдромами. Другое объяснение их совместного рассмотрения - хороший ответ на терапию антидепрессантами. Однако очевидно, что боль как патологический феномен является целой цепью изменений на разных уровнях организма 5 .

По данным литературы, на примере обследования 582 офисных рабочих (средний возраст 45 лет) показана распространенность и взаимосвязь хронической венозной недостаточности нижних конечностей (ХВННК) у 82,6\%, синдрома беспокойных ног (СБН), тревоги (28\%) и депрессивных состояний $(8,6 \%)$. Примерно у каждого четвертого признаки ХВННК сочетались с СБН, расстройствами психологической сферы ${ }^{6}$.

${ }^{4}$ V. Prodanovska-Stojcevska, J. Jovanovic, T. Jovanovska, D. Rajchanovska, I. Filov, B. Bogdanova. The relation between psychosocial work factors and musculoskeletal symptoms among computer workers. Internetional conference on innovations in science and education. March 23-25, 2016, Prague, Czech Republic P. 669-675. DOI 10.12955/cbup.v4.830.

${ }^{5}$ Наумов А.В., Семенов П.А., Верткин А.Л. Стратегия лечения пациентов с болью и соматической патологией. Consilium Medicum. 2010. Т. 12. № 9. С. 111-114.

6 Мазайшвили К.В., Киян К.А., Суханов А.В., Шириязданова Ю.Ф. Распространенность и сочетаемость хронических венозных расстройств нижних конечностей, синдрома беспокойных ног, тревоги и депрессивных состояний среди работников предприятий Московского региона. Флебология. 2019. № 13(1). C. 12-18. DOI 10.17116/flebo20191301112. 
О коморбидности нозологий “офисного синдрома" свидетельствуют данные офтальмологов при исследовании проблемы синдрома "сухого глаза" у офисных работников, где обращено внимание на наличие других офисных вредностей (стрессы, сухой воздух, гиподинамия), приведшие к возникновению мышечно-скелетных болей шеи и психоэмоциональных проблем ${ }^{7}$.

\section{2. Дефиниция офисного синдрома}

Офисный синдром часто в иностранной литературе характеризуется термином "burnout syndrome" (в переводе “синдром выгорания") и описывается как относительно стойкое состояние с постоянной этиологией и симптомами, возникающее в результате воздействия хронического стресса на рабочем месте 8 . Также можно встретить синоним SBS - sick building syndrome - “синдром больного здания".

Концепция выгорания персонала поднималась в зарубежной литературе под термином "stuff burn out" еще в 1974 году и изучалась с точки зрения физических признаков и поведенческих показателей. Было выдвинуто предположение, что подвержен выгоранию самоотверженный и приверженный персонал, что трактовалось как положительный момент с точки зрения работодателя, так и имело отрицательное значение с точки зрения ухудшения здоровья офисного служащего, повлекшего за собой временную утрату нетрудоспособности 9 .

\section{3. Связь средовых факторов офисного помещения с клиническими проявлениями офисного синдрома}

Заслуживает интереса проведённый в Дании анкетный опрос среди 483 офисных работника из 18 государственных учреждений. S.S. Dong и соавт. показали наличие офисного синдрома у 68\% служащих. Наиболее частыми проявлениями были головные боли, мышечноскелетные жалобы, синдром “сухого глаза”, простудные заболевания.

Авторы детально проанализировали качество офисной среды и совокупную степень удовлетворенности офисных работников. Была выявлена наиболее четкая корреляция с температурой воздуха выше 22 градусов, низкой влажностью воздуха, большой степенью

${ }^{7}$ Сафонова Т.Н. “Сухой глаз” - тут виновник не только компьютер. Энергия: экономика, техника, экология. 2010. № 1. С. 68-70.

8 Maslach C., Schaufeli W.B., Leiter M.P. Job Burnout. Annual Review of Psychology. 2001. № 52. P. 397-422.

${ }^{9}$ Herbert J. Freudenberger. Staff Burn-Out. Journal of Social. 1974. Vol. 30, Issue 1. P. 234-242. 
аллергенов, плохая освещенность, ненормированный рабочий день. Также результаты исследований показали достоверное улучшение удовлетворения офисных работников при нормализации офисной среды $^{10}$.

Исследователи Тайвани на примере 389 офисных работников в возрасте от 20 до 65 лет показали связь между личностными факторами и психоэмоциональным стрессом на работе, а также продемонстрировали связь между условиями работы и различными симптомами SBS (“синдром больного здания”)" .

Авторы выделили группу симптомов со стороны глаз, верхних и нижних дыхательных путей, кожи и группу симптомов со стороны нервной системы (головная боль, утомляемость, раздражительность, головокружение, бессонница). Симптомы SBS для глаз чаще возникали у пожилых офисных работников, в коллективах-курильщиков и плохо вентилируемых помещениях. Симптомы верхних дыхательных путей были связаны с курением, низкой социальной поддержкой, продолжительными рабочими днями и сухим воздухом. Симптомы нижних дыхательных путей чаще были у пациентов, отмечающих психоэмоциональное напряжение как дома, так и в рабочих условиях, а также у пациентов с продолжительным рабочим временем, химическим воздействием, мигренью. У пациентов с неврологическими симптомами чаще всего из офисных средовых факторов отмечалось курение, более продолжительный рабочий день, плохая вентилируемость офиса, сухой воздух в нем, а также воздействие летучих органических веществ. Исследователи сделали вывод, что различные симптомы SBS связаны как с различными личностными характеристиками, так и с психосоциальными и экологическими факторами, а также хорошая вентиляция офисного помещения может снизить факторы риска и облегчить симптомы SBS.

Головная боль $(25,4 \%)$, усталость $(20,9 \%)$, трудности с концентрацией внимания $(14,6 \%)$, сухость глаз $(18,7 \%)$ также были частыми жалобами у 417 сотрудников в 87 офисных помещениях. Авторы исследования показали статистически значимую связь между

${ }^{10}$ Dong S.S., Byung Y.J., Myoung H.P. Structural equation modeling of office environment quality, sick building syndrome, and musculoskeletal complaints on aggregate satisfaction of office workers. Human Factors and Ergonomics in Manufacturing. 2018. Vol. 28 (6), Issue 3. P. 101-162. DOI 10.1002/hfm.20730.

${ }^{11}$ Chung-Yen Lu, Meng-Chuan Tsai, Chih-Hsin Muo, Yu-Hsien Kuo, Fung-Chang Sung. Personal, Psychosocial and Environmental Factors Related to Sick Building Syndrome in Official Employees of Taiwan. Int. J. Environ. Res. Public Health. 2018. № 15(1). P. 7-16. DOI 10.3390/ijerph15010007. 
симптомами SBS и содержанием диоксида углерода, летучими органическими соединениями в офисных помещениях ${ }^{12}$.

Коморбидность цефалгии показана в исследовании 1087 офисных ямайских служащих, у которых были мигрени $(16,0 \%)$ в сочетании с артериальной гипертензией (13,5\%), астмой (6,1\%). Кроме того, 33\% работников имели избыточный вес, 16,7\% страдали ожирением, а $10 \%$ были крайне страдающими ожирением. Большинство $\quad(55,1 \%)$ участников исследования сообщили о чрезмерном потреблении фастфуда за последние 7 дней $^{13}$.

Erek K. Helseth и соавт $^{14}$. провели исследование 4325 офисных сотрудников из 100 государственных и частных офисных зданий в 25 штатах Америки и показали, что наиболее частым проявлением SBS является головная боль и боль в шее, которые приводят к высокому уровню нетрудоспособности. Вероятность была выше у пациентов при некомфортных внутренних параметрах окружающей среды на рабочем месте (диоксид углерода, монооксид углерода, температура, относительная влажность, твердые частицы, летучие органические соединения, освещенность и уровень звука). Мигренозный характер боли отмечался у 75\% женщин против 53\% у мужчин. Частота головной боли в течение последних 4 недель была такой: последние 1-3 дня - у 38\%, 1-3 дня в неделю у 18\% и каждый день или почти каждый рабочий день - у 8\% опрошенных офисных работников.

Eltayeb и соавт ${ }^{15}$. изучали взаимосвязь между физическими и психосоциальными характеристиками, связанными с работой, и жалобами на боль в шее, плече и руке у 264 пользователей компьютеров в проспективном голландском когортном исследовании с

12 Lu C.Y., Lin J.M., Chen Y.Y., Chen Y.C. Building-Related Symptoms among Office Employees Associated with Indoor Carbon Dioxide and Total Volatile Organic Compounds Building-Related Symptoms among Office Employees Associated with Indoor Carbon Dioxide and Total Volatile Organic Compounds. Int. J. Environ. Res. Public Health. 2015. № 12(6). P. 5833-5845. DOI 10.3390/ijerph120605833.

13 Lindo J.L., LaGrenade J., Eldemire-Shearer D. The Health of OfficeBased Workers in Kingston, Jamaica. Workplace Health Saf. 2017. № 65(2). P. 74-82. DOI 10.1177/2165079916667735.

${ }^{14}$ Erek K. Helseth, Jay C. Erickson The Prevalence and Impact of Migraine on US Military[Erek K. Helseth, Jay C. Erickson The Prevalence and Impact of Migraine on US Military Officer Trainees. Headache. 2008. № 48 (6). P. 883-9. DOI 10.1111/j.15264610.2007.00962.

${ }^{15}$ Eltayeb, Shahla Staal, J Bart Khamis, Amar Bie, Rob. (2009). Work Related Risk Factors for Neck, Shoulder and Arms Complaints: A Cohort Study Among Dutch Computer Office Workers. Journal of occupational rehabilitation. 2009. № 19. P. 315-22. DOI 10.1007/s10926-009-9196-x. 
периодом наблюдения 2 года. Физические и психосоциальные факторы риска были протестированы, чтобы предсказать возникновение жалоб на шею, плечо и предплечье / руку.

Результаты показали, что факторы риска возникновения верхних мышечно-скелетных жалоб у компьютерных работников состоят из смеси физических и психосоциальных характеристик. К физическим предикторам была отнесена напряженная и неподвижная осанка головы и тела, а к психосоциальным - сложные требования к работе, в том числе жесткие дедлайны, ненормированность рабочего дня, а также наличие ранее жалоб на мышечно-скелетные боли.

Отечественные исследования по офисному синдрому очень ограничены. Чаще рассматриваются аспекты диагностики и лечения головной боли, мышечно-скелетных болей вне связи с профессиональной средой, без учета особенностей диагностики и лечения. Либо же рассматривается как изолированная психологическая проблема “эмоционального выгорания".

\section{4. Собственное исследование}

Цель исследования - изучить клинико-неврологические особенности проявлений офисного синдрома в украинских офисных работников.

Материаль и методы исследования: обследовано 143 пациента, работающих в условиях офиса и обратившихся к неврологу. Из них было 93 женщины, 50 мужчин. Среди них было 114 больных на постоянной работе и 29 - на временной работе.

Распределение пациентов по профессиям отражено в табл. 1. Наибольшее количество больных работали с компьютерами, в кадровой службе, банке, а также занимались финансово-экономической деятельностью.

Все пациенты в зависимости от длительности рабочего дня были распределены следующим образом: первая исследуемая группа (І группа) с длительностью рабочего дня до 8 часов - 5 пациентов (3,5\%), вторая исследуемая группа (II группа) с длительностью 8 часов при 40-часовой рабочей неделе - 89 пациентов (62,24\%), третья исследуемая группа (III группа) с ненормированным рабочим днем более 8 часов (с постоянными ненормированным рабочим временем 49 пациентов $(34,26 \%)$.

Обследование пациентов включало сбор анамнеза, определение ведущего клинического неврологического синдрома, выяснение сопутствующей патологии. Так как в МКБ-10 отсутствует формулировка “офисный синдром”, то выявленная патология 
диагностировались в зависимости от преобладающей неврологической симптоматики (табл. 2).

Таблица 1

\section{Распределение пациентов по профессиям}

\begin{tabular}{|l|c|}
\hline \multicolumn{1}{|c|}{ Профессиональная отрасль } & Количество \\
\hline HR, кадровые службы, IT, компьютеры, дизайн & 34 \\
\hline Маркетинг, реклама и РR & 10 \\
\hline Медицина & 5 \\
\hline Недвижимость, строительство, архитектура & 7 \\
\hline Образование и педагогика & 3 \\
\hline Секретариат, делопроизводство & 11 \\
\hline СМИ, издательство, полиграфия & 14 \\
\hline Страхование & 5 \\
\hline Телекоммуникации и связь & 2 \\
\hline Техника, технологии, производство & 13 \\
\hline $\begin{array}{l}\text { Торговля, логистика, внешнеэкономическая } \\
\text { деятельность }\end{array}$ & 10 \\
\hline Финансы, бухгалтерия, банк & 29 \\
\hline
\end{tabular}

Пациентам с психо-эмоциональными нарушениями с целью выявления способов борьбы со стрессом на работе и фрустрацией, выявления уровня самоотверженности работника использовался опросник BCSQ-36. Опросник помогает выявить подтип эмоционального выгорания и может быть использован как средство для разработки и оценки различных превентивных и действующих подходов для борьбы с выгоранием на рабочем месте ${ }^{16}$.

Всем больным были проведены клинический анализ крови, мочи, биохимический анализ крови, МНО, липидный спектр крови. Всем пациентам с фокальной неврологической симптоматикой проведено магнитно-резонансно-томмографическое исследование головного мозга. Пациентам с мышечно-скелетными болями проводилось рентгенологическое или магнитно-резонансное исследование позвоночника.

$\mathrm{C}$ нейрофункциональных методов исследования всем больным проводилось ультразвуковое исследование сосудов шеи и транскраниальная допплерография сосудов головного мозга, по

${ }^{16}$ Montero-Marín J., García-Campayo J. A newer and broader definition of burnout: Validation of the "Burnout Clinical Subtype Questionnaire (BCSQ-36)". BMC Public Health. 2010. № 10, p. 302. DOI 10.1186/1471-2458-10-302. 
показаниям проводилось ультразвуковое исследование сосудов нижних конечностей. Все пациенты проконсультированы офтальмологом с проведением офтальмоскопии, при наличии соответствующих клинических синдромов - консультированы смежными специалистами (эндокринологом, кардиологом, гинекологом и другими)

Гендерное распределение и по возрасту обследуемых пациентов отображено в табл. 2.

Таблица 2

Распределение пациентов по возрасту и полу (абсол. знач.,\%)

\begin{tabular}{|c|c|c|c|c|c|c|}
\hline & \multicolumn{2}{|c|}{ Первая группа (n = 5) } & \multicolumn{2}{|c|}{$\begin{array}{c}\text { Вторая группа } \\
(\mathbf{n}=\mathbf{8 9})\end{array}$} & \multicolumn{2}{|c|}{$\begin{array}{c}\text { Третья группа } \\
(\mathrm{n}=\mathbf{4 9})\end{array}$} \\
\hline & $\begin{array}{c}\text { Мужчины } \\
(\mathrm{n}=3)\end{array}$ & $\begin{array}{c}\text { Женщины } \\
(\mathrm{n}=2)\end{array}$ & $\begin{array}{c}\text { Мужчины } \\
(\mathrm{n}=40)\end{array}$ & $\begin{array}{c}\text { Женщины } \\
(\mathrm{n}=49)\end{array}$ & $\begin{array}{c}\text { Мужчины } \\
(\mathrm{n}=26)\end{array}$ & $\begin{array}{c}\text { Женщины } \\
(\mathrm{n}=23)\end{array}$ \\
\hline $\begin{array}{c}20-30 \\
\text { лет }\end{array}$ & $\begin{array}{c}1(33,33 \pm \\
0,23)\end{array}$ & $\begin{array}{c}1 \\
(50 \pm \\
0,78)\end{array}$ & $\begin{array}{c}5 \\
(12,5 \pm \\
0,02)\end{array}$ & $\begin{array}{c}7 \\
(14,29 \pm \\
0,12)\end{array}$ & $\begin{array}{c}4 \\
(15.39 \pm \\
0,78)\end{array}$ & $\begin{array}{c}3 \\
(13,04 \pm \\
0,78)\end{array}$ \\
\hline $\begin{array}{c}31-40 \\
\text { лет }\end{array}$ & 0 & $\begin{array}{c}1 \\
(50 \pm \\
0,64)\end{array}$ & $\begin{array}{c}17 \\
(42,5 \pm \\
0,34)\end{array}$ & $\begin{array}{c}21 \\
(42,86 \pm \\
0,25)\end{array}$ & $\begin{array}{c}10 \\
(38,46 \pm \\
0,21)\end{array}$ & $\begin{array}{c}8 \\
(34,78 \pm \\
0,23)\end{array}$ \\
\hline $\begin{array}{c}41-50 \\
\text { лет }\end{array}$ & $\begin{array}{c}1 \\
(33,33 \pm \\
0,24)\end{array}$ & 0 & $\begin{array}{c}16 \\
(40,0 \pm \\
0,22)\end{array}$ & $\begin{array}{c}18 \\
(36,75 \pm \\
0,11)\end{array}$ & $\begin{array}{c}10 \\
(38,46 \pm \\
0,12)\end{array}$ & $\begin{array}{c}12 \\
(52,17 \pm \\
0,35)\end{array}$ \\
\hline $\begin{array}{c}51-60 \\
\text { лет }\end{array}$ & $\begin{array}{c}1 \\
(33,33 \pm \\
0,28)\end{array}$ & 0 & $\begin{array}{c}2 \\
(5,0 \pm \\
0,02)\end{array}$ & $\begin{array}{c}3 \\
(6,12 \pm \\
0,13)\end{array}$ & $\begin{array}{c}2 \\
(7,69 \pm \\
0,21)\end{array}$ & 0 \\
\hline
\end{tabular}

Наиболее частой жалобой у пациентов второй и третьей группы была локальная боль в затылке (44\%) или диффузная головная боль давящего характера (11\%), которая преимущественно отмечалась в лобно-височной области. Головокружение чаще $(\mathrm{p}<0,05)$ было у пациентов с поражением шейных корешков и явлениями сдавления а. vertebralis - 23\% пациентов II группы и $18 \%$ III группы.

Анализируя анамнез пациентов, большинством пациентов с цефалгиями было отмечено, что они максимум рабочего времени (от 8 часов и более) проводили за компьютером, в внутренней офисной среде был сухой воздух в плохо вентилируемых помещениях, в офисной мебели преобладали пластиковые материалы, пациенты отмечали 
некомфортное воздействие “оpen spase”, a также наличие большого количества коллег-курильщиков, нерегулярное питание, которое было нередко в системе “быстрого питания”, несоблюдение питьевого режима, постоянное воздействие стресса, жестких дедлайнов.

Мышечно-скелетная боль была распространенной жалобой у всех пациентов: у пациентов III группы достоверно чаще $(\mathrm{p}<0,05)$ боль была пояснично-крестцовой (43\%) и грудной локализации $(11 \%)$, а также чаще встречался синдром "запястного канала"; у пациентов I группы отмечалось наличие болей в спине до работы в офисе; а у пациентов II и III групп примерно в равной степени (в 41\% случаев) встречалась боль в шее. В анамнезе у пациентов с мышечноскелетными болями преобладали воздействие компьютера, сидячая рабочая поза, нередко в напряженной позе с наклоненной и выдвинутой вперед головой, гиподинамия. Вертебрологический статус наиболее часто обнаруживал шейный кифоз, гиперлордоз пояснично-крестцового отдела, сколиоз, отечность ромба Михаэлиса.

У 40,2\% больных II группы и 50,8\% больных III группы отмечалась утомляемость, общая слабость, трудность с концентрацией внимания и не встречались данные жалобы в I группе. Офисные пациенты, работающие 8 и более часов также отмечали повышенную конфликтность, тревожность, снижение физической и умственной работоспособность, эмоциональную неустойчивость. Этим пациентам проводилось анкетирование по опроснику BCSQ-36.

В неврологическом статусе наиболее часто были нарушения черепной иннервации в виде слабости конвергенции, отмечалось нарушение статики и координации при явлениях хронической ишемии мозга и синдрома a. vertebralis. Нарушение рефлекторной сферы с признаками пирамидной, сенсо-пирамидной недостаточности наблюдались у пациентов старше 51 года в группе с ненормированным рабочим днем и расценивалось как дисциркуляторная энцефалопатия. Вегетативная недостаточность в виде повышенной потливости, акроцианоза одинаково часто встречались во всех группах, нередко встречалась у больных в анамнезе до начала работы в офисных условиях.

Распределение пациентов по ведущей неврологической нозологии отражено в таблице 3. 
Таблица 3

Распределение пациентов по ведущей неврологической нозологии

\begin{tabular}{|c|c|c|c|}
\hline & $\begin{array}{c}\text { Первая группа } \\
(\mathbf{n}=\mathbf{5})\end{array}$ & $\begin{array}{c}\text { Вторая группа } \\
(\mathbf{n}=\mathbf{8 9})\end{array}$ & $\begin{array}{c}\text { Третья группа } \\
(\mathrm{n}=49)\end{array}$ \\
\hline 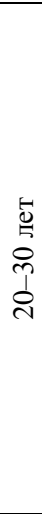 & $\begin{array}{l}\text { G 54.3 Поражение } \\
\text { грудных корешков - } 1 \\
\text { G 58.0 Межреберная } \\
\text { мононевропатия - } 1\end{array}$ & $\begin{array}{l}\text { G } 54.2 \text { Поражение } \\
\text { шейных корешков - } 1 \\
\text { G } 54.3 \text { Поражение } \\
\text { грудных корешков - } 1 \\
\text { G } 54.4 \text { Поражение } \\
\text { пояснично-крестцовых } \\
\text { корешков - } \\
\text { G 55.1 Сдавление } \\
\text { нервных корешков и } \\
\text { сплетений } \\
\text { при нарушении } \\
\text { межпозвоночных } \\
\text { дисков - } 7 \\
\text { G 43.0. Мигрень без } \\
\text { ауры - 1 }\end{array}$ & $\begin{array}{l}\text { G 56.0 Синдром } \\
\text { запястного канала - } 1 \\
\text { G 55.1 Сдавление } \\
\text { нервных корешков и } \\
\text { сплетений при } \\
\text { нарушении } \\
\text { межпозвоночных } \\
\text { дисков - } 4 \\
\text { G } 90.0 \text { Расстройства } \\
\text { автономной } \\
\text { (вегетативной) } \\
\text { нервной системы - } 1 \\
\text { G 43.0. Мигрень без } \\
\text { ауры - 1 }\end{array}$ \\
\hline 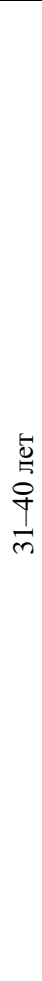 & $\begin{array}{l}\text { G } 90.0 \text { Расстройства } \\
\text { автономной } \\
\text { (вегетативной) } \\
\text { нервной системы - } 1\end{array}$ & $\begin{array}{l}\text { G 54.2 Поражение } \\
\text { шейных корешков -6 } \\
\text { G } 54.3 \text { Поражение } \\
\text { грудных корешков - } 1 \\
\text { G } 54.4 \text { Поражение } \\
\text { пояснично-крестцовых } \\
\text { корешков - } 7 \\
\text { G 55.1 Сдавление } \\
\text { нервных корешков и } \\
\text { сплетений } \\
\text { при нарушении } \\
\text { межпозвоночных } \\
\text { дисков - 10 } \\
\text { G 56.0 Синдром } \\
\text { запястного канала - } 4 \\
\text { G 56.2 Поражение } \\
\text { локтевого нерва - } 1 \\
\text { G 58.0 Межреберная } \\
\text { мононевропатия - } 2 \\
\text { G } 90.0 \text { Расстройства } \\
\text { автономной } \\
\text { (вегетативной) } \\
\text { нервной системы - } 1 \\
\text { G } 43.0 . \text { Мигрень без } \\
\text { ауры - } 3 \\
\text { I.65.0 Закупорка и } \\
\text { стеноз } \\
\text { прецеребральных } \\
\text { артерий - } 3\end{array}$ & $\begin{array}{l}\text { G 50.0 Поражение } \\
\text { плечевого сплете- } \\
\text { ния - } 1 \\
\text { G } 54.4 \text { Поражение } \\
\text { пояснично-крестцовых } \\
\text { корешков - } 5 \\
\text { G 55.1 Сдавление } \\
\text { нервных корешков и } \\
\text { сплетений } \\
\text { при нарушении } \\
\text { межпозвоночных } \\
\text { дисков - 5 } \\
\text { G 56.0 Синдром } \\
\text { запястного канала - } 1 \\
\text { G 56.2 Поражение } \\
\text { локтевого нерва - } 1 \\
\text { G 43.0. Мигрень без } \\
\text { ауры - } 5\end{array}$ \\
\hline
\end{tabular}


Закінчення таблиці 3

\begin{tabular}{|c|c|c|c|}
\hline & $\begin{array}{c}\text { Первая группа } \\
(\mathrm{n}=\mathbf{5})\end{array}$ & $\begin{array}{c}\text { Вторая группа } \\
(\mathrm{n}=\mathbf{8 9})\end{array}$ & $\begin{array}{c}\text { Tретья группа } \\
(\mathrm{n}=49)\end{array}$ \\
\hline \begin{tabular}{l}
\multirow{2}{0}{} \\
$\stackrel{5}{0}$ \\
$\stackrel{n}{1}$ \\
$\frac{1}{\gamma}$
\end{tabular} & $\begin{array}{l}\text { G } 57.0 \text { Поражение } \\
\text { седалищного нерва - } 1\end{array}$ & $\begin{array}{l}\text { G 54.2 Поражение } \\
\text { шейных корешков - } 5 \\
\text { G } 54.3 \text { Поражение } \\
\text { грудных корешков - } 1 \\
\text { G } 54.4 \text { Поражение } \\
\text { пояснично-крестцовых } \\
\text { корешков - } \\
\text { G 55.1 Сдавление } \\
\text { нервных корешков и } \\
\text { сплетений } \\
\text { при нарушении } \\
\text { межпозвоночных } \\
\text { дисков - } 9 \\
\text { G } 56.0 \text { Синдром } \\
\text { запястного канала - } 5 \\
\text { G 58.0 Межреберная } \\
\text { мононевропатия - } 1 \\
\text { G } 43.0 . \text { Мигрень без } \\
\text { ауры - } 2 \\
\text { I.65.0 Закупорка и } \\
\text { стеноз } \\
\text { прецеребральных } \\
\text { артерий - } 2\end{array}$ & $\begin{array}{l}\text { G 50.0 Поражение } \\
\text { плечевого сплетения } \\
-1 \\
\text { G } 54.1 \text { Поражение } \\
\text { пояснично- } \\
\text { крестцового } \\
\text { сплетения - } 1 \\
\text { G } 55.1 \text { Сдавление } \\
\text { нервных корешков и } \\
\text { сплетений при } \\
\text { нарушении } \\
\text { межпозвоночных } \\
\text { дисков - 6 } \\
\text { G 55.2 при } \\
\text { спондилезе - } 2 \\
\text { G 56.0 Синдром } \\
\text { запястного канала - } 5 \\
\text { G 58.0 Межреберная } \\
\text { мононевропатия - } 1 \\
\text { G 43.0. Мигрень без } \\
\text { ауры - 4 } \\
\text { I.65.0 Закупорка и } \\
\text { стеноз прецеребраль- } \\
\text { ных артерий, не } \\
\text { приводящих к } \\
\text { инфаркту мозга, - } 2\end{array}$ \\
\hline $\begin{array}{l}\overrightarrow{0} \\
\stackrel{5}{5} \\
0 \\
\frac{1}{n} \\
n\end{array}$ & $\begin{array}{l}\text { G 58.0 Межреберная } \\
\text { мононевропатия - } 1\end{array}$ & $\begin{array}{l}\text { G 50.0 Поражение } \\
\text { плечевого сплете- } \\
\text { ния - } 1 \\
\text { G 55.1 Сдавление } \\
\text { нервных корешков и } \\
\text { сплетений при } \\
\text { нарушении } \\
\text { межпозвоночных } \\
\text { дисков - } 3 \\
\text { I.65.0 Закупорка и } \\
\text { стеноз прецеребраль- } \\
\text { ных артерий - } 1\end{array}$ & $\begin{array}{l}\text { I.67.9 Церебро- } \\
\text { васкулярная болезнь } \\
\text { (дисциркуляторная } \\
\text { энцефалопатия) - } 2\end{array}$ \\
\hline
\end{tabular}

При детальном клинико-неврологическом обследовании исследуемых групп выявлена сопутствующая патология, которая расценена как фон для формирования коморбидной патологии. Термин "comorbidity" предложен A.R. Feinsten в 1970 году для обозначения сосуществования у одного пациента двух и более синдромов или 
заболеваний. Коморбидность следует отличать от мультиморбидности, поскольку причинная коморбидность подразумевает сочетание у одного больного двух и более заболеваний, патогенетически взаимосвязанных между собой. Это разделение и понимание офисного синдром как комплекса коморбидных состояний, по ммнению автора, принципиально, так как это позволяет адекватно оценить объем и тяжесть поражения, оптимизирует раннюю активную профилактику и комплексную терапию с учётом единого патогенетического механизма - стресс. Это означает, что при определённых условиях стресс-синдром из общего неспецифического звена адаптации организма к различным факторам среды превращается в общее неспецифическое звено заболеваний.

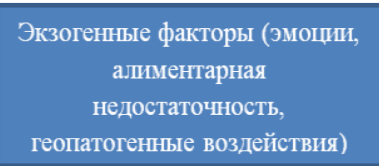

Эндогеншые факторы (боль,

нарушение гомеостаза, страх,

тревога)

Стресс-реакции

\section{Рис. 1. Патогенетические механизмы стресса при “офисном синдроме" (Ф.3. Меерсон, 1986, с дополнениями автора)}

Из сопутствующей патологии наиболее часто встречались атеросклероз, гипертоническая болезнь, нарушения ритма и проводимости сердца, синдром "сухого глаза", хронический гастрит, гастродуоденит, язва 12-перстной кишки, хронический колит, частые простудные заболевания, геморрой и трещины прямой кишки, хронические воспалительные заболевания органов малого таза (хронический простатит у мужчин, хронический эндометриоз, сальпингоофорит у женщин), ожирение, варикозное расширение вен нижних конечностей, сахарный диабет без конечно-органных поражений. 
Всем больным проводилась объективная оценка коморбидного статуса, которая чрезвычайно важна и предполагает использование унифицированных шкал и индексов, которые могли быть успешно применены в клинической практике. В этой связи вызывает интерес индекс коморбидности Charlson ${ }^{17}$, который использовали в собственной модификации с включением дополнительных параметров актуальных для рассмотрения коморбидной патологии “офисного синдрома”.

Таблица 4

\section{Бальная оценка наличия сопутствующих заболеваний при расчёте индекса коморбидности Чарлсона (по Charlson M.E., 1987, с дополнениями автора)}

\begin{tabular}{|l|c|}
\hline \multicolumn{1}{|c|}{ Сопутствующее заболевание } & Балл \\
\hline Атеросклероз & 2 \\
\hline Гипертоническая болезнь & 2 \\
\hline Нарушения ритма и проводимости сердца & 2 \\
\hline Синдром “сухого глаза” & 1 \\
\hline Хронический гастрит, гастродуоденит & 1 \\
\hline Язва 12-перстной кишки & 1 \\
\hline Хронический колит & 1 \\
\hline Частые простудные заболевания & 1 \\
\hline Геморрой и трещины прямой кишки & 1 \\
\hline $\begin{array}{l}\text { Хронические воспалительные заболевания органов малого таза - } \\
\text { хронический простатит (для мужчин) }\end{array}$ & 1 \\
\hline $\begin{array}{l}\text { Хронические воспалительные заболевания органов малого таза - } \\
\text { хронический эндометриоз, сальпингоофорит (для женщин) }\end{array}$ & 1 \\
\hline Ожирение & 2 \\
\hline Варикозное расширение вен нижних конечностей & 1 \\
\hline Сахарный диабет без конечно-органных поражений & 2 \\
\hline Всего баллов & \\
\hline
\end{tabular}

Таблица 5

Распределение суммарного балла Чарлсона в исследуемых группах

\begin{tabular}{|c|l|l|l|}
\hline & \multicolumn{1}{|c|}{ Первая группа } & $\begin{array}{c}\text { Вторая } \\
\text { группа }\end{array}$ & \multicolumn{1}{|c|}{ Третья группа } \\
\hline $20-30$ лет & $0,28 \pm 0,12$ & $1,49 \pm 0,25$ & $4,49 \pm 1,30$ \\
\hline $31-40$ лет & $0,32 \pm 1,2$ & $2,38 \pm 0,78^{*}$ & $3,82 \pm 1,50$ \\
\hline $41-50$ лет & $1,24 \pm 1,50$ & $5,24 \pm 1,50^{*}$ & $6,38 \pm 1,76$ \\
\hline $51-60$ лет & $1,38 \pm 0,87$ & $6,49 \pm 1,50$ & $9,49 \pm 1,23$ \\
\hline
\end{tabular}

Примечание: " $\mathrm{p}<0,05$

${ }^{17}$ Charlson M.E, Pompei P, Ales K.L, McKenzie C.R. A new method of classifying prognostic comorbidity in longitudinal studies: development and validation. J. Chron. Dis. 1987. № 40(5). P. 373-383. 
Анализ индекса Чарлсона (табл. 5) показал, что наиболее высоким балл был в II и III группах: $6,49 \pm 1,50$ и 9,49 $\pm 1,23$ соответственно. Наиболее частыми коморбидными патологиями в исследуемых группах были атеросклероз (32\%), ожирение (14\%), артериальная гипертензия $(21 \%)$, варикозное расширение вен нижних конечностей $(16 \%)$, нарушения ритма и проводимости $(0,02 \%)$, имеющие высокие сердечно-сосудистые риски.

Среди пациентов возрастной категории 31-40 лет II исследуемой группы наиболее распространенными патологиями были ожирение, артериальная гипертензия, а возрастной категории 41-50 лет II исследуемой группы, кроме ожирения и артериальной гипертензии, достоверно возрастала частота атеросклероза, частых простудных заболеваний, хронических воспалительных заболеваний органов малого таза; среди них преобладали лица, имеющие постоянную рабочую занятость - 20 (78\%).

Среди респондентов III группы достоверно тяжелее был коморбидный фон в возрастной категории 51-60 лет, наиболее встречаемой патологией был хронический гастрит, гастродуоденит (25\%), сахарный диабет (1\%), гипертоническая болезнь, ожирение, а в возрастной категории 41-50 лет гипертоническая болезнь, ожирение, синдром “сухого глаза" (14\%).

Тип отношения к работе и риск развития эмоционального выгорания выясняли путем анкетирования по опроснику BCSQ-36, где исследуемые отвечали на вопросы, содержащие различные смоделированные рабочие ситуации. Всего в опросе приняли участие 76\% испытуемых. Было выделено три подтипа: фанатичный, немотивированный и уставший.

Фанатичный подтип включал в себя наиболее включенных и преданных работе людей, самоотверженно вкладывающих в свою профессию огромные временные ресурсы и значительные усилия. Такие люди склонны увеличивать объем прилагаемых усилий при возникновении трудностей; им свойственны амбициозность и необходимость достигать значительных успехов; они также склонны брать на себя чрезмерную нагрузку, приводящую к пренебрежению собственными нуждами (в отношении личной жизни и здоровья) в попытке выполнить все обязанности и удовлетворить все требования, которые перед ним ставит их профессия.

Немотивированный подтип включал в себя людей, которые не заинтересованы в своей работе и выполняют свои обязанности поверхностно, так как им не хватает мотивации или желания 
вовлекаться в работу в большей степени. Этот подтип выгорания характеризуется равнодушием, отсутствием интереса к работе, недостатком развития, который может возникать из-за неудовлетворенности и недостаточного признания талантов работника именно в этой профессии. Такой человек воспринимает работу как скучное и монотонное занятие.

Уставщий подтип включает людей, чей уровень вовлеченности в работу уменьшился до такой степени, что они начали пренебрегать своими профессиональными обязанностями. Этому подтипу свойственны пренебрежение и заброшенность своих обязанностей при возникновении трудностей человек просто сдается; недостаток ощущения значимости, так как человек не чувствует, что его усилия и вложения признаются другими; недостаток контроля над результатами своей работы и даже отчаяние.

Результаты анкетирования по опроснику BCSQ-36 отражены в табл. 6 и показывают наибольший процент фанатичного типа отношения к работе среди офисных работников II и III исследуемых группах, особенно в группе с ненормированным рабочим днем (средний балл по анкетированию 3,87 против 3,15 баллов).

Результаты также отличались для временных и постоянных работников. Временные работники чаще относились к фанатичному типу отношения к работе, а постоянные показали более высокие результаты по немотивированному и уставшему.

Таблица 6

Результаты анкетирования по опроснику BCSQ-36

\begin{tabular}{|l|c|c|c|}
\hline & I группа & I группа & III группа \\
\hline Фанатичный & 2,4 & 3,15 & 3,87 \\
\hline Немотивированный & 1,12 & 2,15 & 2,42 \\
\hline Уставший & 1,15 & 2,07 & 2,32 \\
\hline
\end{tabular}

Биохимическое исследование крови у всех больных было без существенных отклонений от нормы, а данные коагулограммы достоверно $(\mathrm{p}<0,05)$ коррелировали с тяжестью цереброваскулярного поражения, особенно у пациентов второй и третьей исследуемой группы в возрасте 41-50 и 51-60 лет.

Исследование липидного обмена (табл. 7) обнаруживало изменения, которые были достоверно выше в возрастных группах 41-50 и 51-60 лет второй и третьей исследуемых групп. 
Таблица 7

Показатели липидного обмена в исследуемых группах

\begin{tabular}{|l|c|c|c|}
\hline & I группа & II группа & III группа \\
\hline $\begin{array}{l}\text { Общий холестерин, } \\
\text { ммоль/л }\end{array}$ & $3,42 \pm 0,32$ & $4,49 \pm 0,38$ & $4,59 \pm 1,34 *$ \\
\hline $\begin{array}{l}\text { Триглицериды, } \\
\text { ммоль/л }\end{array}$ & $1,32 \pm 0,31$ & $1,48 \pm 1,10$ & $1,82 \pm 1,50^{*}$ \\
\hline $\begin{array}{l}\text { Липопротеиды высокой } \\
\text { плотности, ммоль/л }\end{array}$ & $0,24 \pm 0,02^{*}$ & $0,39 \pm 0,12$ & $0,38 \pm 1,76$ \\
\hline $\begin{array}{l}\text { Липоротеиды очень } \\
\text { низкой плотности, } \\
\text { ммоль/л }\end{array}$ & $2,28 \pm 0,12^{*}$ & $3,04 \pm 0,17 *$ & $3,68 \pm 0,25 *$ \\
\hline Индекс атерогенности & $2,32 \pm 0,02^{*}$ & $4,35 \pm 0,64 *$ & $4,82 \pm 0,04 *$ \\
\hline
\end{tabular}

Примечание: ${ }^{*} \mathrm{p}<0,05$

Важное значение в течении офисного синдрома играют морфологические изменения строения экстракраниальных сосудов головного мозга, поскольку патологические изгибы и извитость могут негативно отражаться на церебральной гемодинамике. Распределение больных по морфологическим особенностям экстракраниальных сосудов головного мозга представлено в табл. 8.

Таблица 8

\section{Распределение больных в исследуемых группах по морфологическим особенностям экстракраниальных сосудов головного мозга (\%)}

\begin{tabular}{|l|c|c|c|}
\hline & Первая группа & Вторая группа & Третья группа \\
\hline $\begin{array}{l}\text { Патологическая } \\
\text { извитость ПВСА }\end{array}$ & $0,28 \pm 0,12$ & $1,49 \pm 0,25$ & $4,49 \pm 1,30$ \\
\hline $\begin{array}{l}\text { Патологическая } \\
\text { извитость ЛВСА }\end{array}$ & $0,32 \pm 1,2$ & $2,38 \pm 0,78$ & $3,82 \pm 1,50$ \\
\hline $\begin{array}{l}\text { Патологическая } \\
\text { извитость ПОСА }\end{array}$ & $1,24 \pm 1,50$ & $5,24 \pm 1,50^{*}$ & $6,38 \pm 1,76$ \\
\hline $\begin{array}{l}\text { Патологическая } \\
\text { извитость ЛОСА }\end{array}$ & $1,38 \pm 0,87$ & $6,49 \pm 1,50^{*}$ & $9,49 \pm 1,23$ \\
\hline $\begin{array}{l}\text { S-образная } \\
\text { извитость ППА }\end{array}$ & $0,28 \pm 0,12$ & $1,49 \pm 0,25$ & $4,49 \pm 1,30$ \\
\hline $\begin{array}{l}\text { S -образная } \\
\text { извитость ЛПА }\end{array}$ & $0,24 \pm 0,17$ & $2,37 \pm 0,22$ & $3,24 \pm 0,14$ \\
\hline
\end{tabular}

Примечание: ПВСА - правая внутренняя сонная артерия, ЛВСА - левая втуренняя сонная артерия, ПОСА - правая общая сонная артерия, ЛОСА - левая общая сонная артерия, ЛПА - левая позвоночная артерия, ППА - правая позвоночная артерия; $\mathrm{p}<0,05$ 
Анализируя табл. 8, можно с уверенностью сказать, что патологическая извитость и изгибы брахиоцефальных сосудов достоверно выше наблюдалась у пациентов с рабочим графиком от 8 часов и более в день по сравнению с пациентами с рабочим днем менее 8 часов. По результатам допплерографии сосудов шеи атеросклеротические бляшки в брахиоцефальных артериях выявлены в правой сонной артерии у двух работников II исследуемой группы, обоих сонных артериях у одного работника с ненормированным рабочим графиком из III исследуемой группы.

Стенозирование левой внутренней сонной артерии выявлено у четырех пациентов II группы и у одного пациента III группы; у двух пациентов третьей группы бляшки локализовались только в правой внутренней сонной артерии. Все стенозы были гемодинамически незначимы со степенью стеноза до $60 \%$. Толщина комплекса интимамедиа внутренней сонной артерии составляла в I группе 0,54 $\pm 0,12$, в II группе $-0,86 \pm 1,1$ и $0,89 \pm 1,2$ соответственно.

По результатам морфологического исследования сосудов шеи у $68 \%$ больных выявлялись признаки венозного застоя, достоверно чаще обнаруживались они у больных с болью в шее и плечевом поясе. В большинстве случаев цервикокраниалгия характеризовалась как компрессионный синдром позвоночной артерии, что подтверждалось данными объективного вертебрологического статуса и допплерографии в виде экстравазальной компрессии позвоночной артерии.

Мышечно-скелетный болевой синдром у большинства больных был обусловлен поражением позвонков, межпозвонковых дисков, фасеточных суставов, а также связок и мышц позвоночника. Самыми распространенными причинами, обнаруженными при рентгенографии и/или магнитно-резонансной томографии позвоночника при боли в шее и спине являлись патология межпозвонковых дисков с компрессией невральных структур у 29 больных первой группы и 11 больных третьей исследуемой группы, без компрессии - 32 больных II группы и 8 больных III группы; а также обнаруживались спондилоартроз, унковертебральный артроз, у 5 больных аномалия Киммерли. В случае дегенеративной патологии межпозвонкового диска боль обусловлена раздражением фиброзного кольца и/или дурального мешка.

Результаты МРТ головного мозга продемонстрировали у двух больных третьей группы мультифокальное поражение белого вещества головного мозга, перивентрикулярные очаги лейкоареоза, очаги ишемии в медиальных отделах таламуса, что расценено как проявление хронической ишемии мозга (дисциркуляторной энцефалопатии). У 5 больных второй группы и 7 больных третьей исследуемой группы 
обнаружено наличие расширенного субарахноидального пространства и признаки перенесенного синусита с формированием кист гайморовой пазухи. Этим пациентом рекомендована дополнительная консультация отоларинголога и стоматолога.

\section{ВЫВОДЫ}

1. Офисный синдром - собирательное понятие нозологий, развивающихся в офисных работников под воздействием неблагоприятных средовых факторов офисного помещения. Наиболее неблагоприятным воздействием обладает воздействие компьютера, ненормированный рабочий день (более 8 часов), воздействие стресса, гиподинамия, статичное напряжение головы и шеи, неправильное питание.

2. Клинико-неврологические особенности офисного синдрома включают цефалгию, мышечно-скелетную боль, синдром запястного канала, нередко сочетающиеся с коморбидной патологией: атеросклероз (32\%), ожирение (14\%), артериальная гипертензия (21\%), варикозное расширение вен нижних конечностей (16\%), нарушения ритма и проводимости $(0,02 \%)$, атеросклероз $(32 \%)$, ожирение $(14 \%)$, артериальная гипертензия (21\%), варикозное расширение вен нижних конечностей $(16 \%)$, нарушения ритма и проводимости $(0,02 \%)$.

3. Выявлены потенциальные риски взаимосвязи между осанкой и патологией костно-мышечной системы у офисного работника.

4. Факторы риска мышечно-скелетной боли при “офисном синдроме" находятся в тесной связи с отношением к работе. Наиболее часто мышечно-скелетные боли возникают при фанатичном отношении к работе и у работников с ненормированным рабочим днем.

5. Исследование морфологического строения брахиоцефальных сосудов шеи позволило выявить патологическую извитость, изгибы позвоночной артерии, признаки прецеребрального стенозирования, венозного застоя (чаще у пациентов с ненормированным рабочим днем).

6. Анализ факторов риска “офисного синдрома", клиниконеврологических особенностей важен для адекватной комплексной оценки и своевременного проведения превентивных мероприятий по организации офисного пространства.

\section{АННОТАЦИЯ}

Патогенные факторы риска для возникновения “офисного синдрома" -гиподинамия, большое скопление людей, организация "open spase", ненормированный рабочий график, стрессы, неправильное и нерегулярное питание, концентрированное количество аллергенов. 
В статье приведены результаты обследования 142 офисных украинских работников, которые были разделены на три группы: первая исследуемая группа (I группа) с длительностью рабочего дня до 8 часов - 5 пациентов (3,5\%), вторая исследуемая группа (II группа) с длительностью 8 часов при 40-часовой рабочей неделе - 89 пациентов (62,24\%), третья исследуемая группа (III группа) с ненормированным рабочим днем более 8 часов (с постоянными ненормированным рабочим временем - 49 пациентов $(34,26 \%)$.

Клинико-неврологические особенности офисного синдрома включают цефалгию, мышечно-скелетную боль, синдром запястного канала. Наиболее частой жалобой у пациентов второй и третьей группы была локальная боль в затылке $(44 \%)$, диффузная головная боль давящего характера (11\%). Головокружение достоверно чаще $(\mathrm{p}<0,05)$ было у пациентов с поражением шейных корешков и явлениями сдавления a. vertebralis - 23\% пациентов II группы и $18 \%$ III группы.

Мышечно-скелетная боль была распространенной жалобой у всех пациентов: у пациентов III группы достоверно чаще $(\mathrm{p}<0,05)$ боль была пояснично-крестцовой $(43 \%)$ и грудной локализации $(11 \%)$, а также встречался синдром “запястного канала"; у пациентов I группы отмечалось наличие болей в спине до работы в офисе; а у пациентов II и III групп примерно в равной степени (41\% случаев) встречалась боль в шее.

Наиболее частыми коморбидными патологиями в исследуемых группах были атеросклероз (32\%), ожирение (14\%), артериальная гипертензия (21\%), варикозное расширение вен нижних конечностей $(16 \%)$, нарушения ритма и проводимости $(0,02 \%)$, имеющие высокие сердечно-сосудистые риски.

Среди пациентов возрастной категории 31-40 лет II исследуемой группы наиболее распространенными патологиями были ожирение, артериальная гипертензия, а в возрастной категории 41-50 лет II исследуемой группы, кроме ожирения и артериальной гипертензии, достоверно возрастала частота атеросклероза, частых простудных заболеваний, хронических воспалительные заболевания органов малого таза.

Среди респондентов III группы достоверно тяжелее был коморбидный фон в возрастной категории 51-60 лет, наиболее встречаемой патологией были хронический гастрит, гастродуоденит (25\%), сахарный диабет (1\%), гипертоническая болезнь, ожирение, а в возрастной категории 41-50 лет - гипертоническая болезнь, ожирение, синдром “сухого глаза” (14\%). 
По результатам допплерографии сосудов шеи обнаруживалась патологическая извитость, изгибы позвоночной артерии, признаки прецеребрального стенозирования, а также венозного застоя (чаще у пациентов с ненормированным рабочим днем).

Автор обосновывает необходимость анализа факторов риска “офисного синдрома", клинико-неврологических особенностей для адекватной комплексной оценки и своевременного проведения превентивных мероприятий по организации офисного пространства.

\section{ЛИТЕРАТУРА}

1. Данилов А.Б., Курганова Ю.М. Офисный синдром. Медицина неотложных состояний. 2012. № 7-8 (46-47) С. 167-173.

2. Karasek R., Theorell T. Healthy Work, Stress, Productivity and the Reconstruction of Working Life. Basic Books Inc. Publishers, New-York. 1990. $756 \mathrm{p}$.

3. Bongers P., Kremer. Are psychosocial factors, risk factors for symptoms and signs of the shoulder, elbow, or hand / wrist? a review of the epidemiological literature. American Journal of Industrial Medicine. 2002. № 41. P. 315-342.

4. V. Prodanovska-Stojcevska, J. Jovanovic, T. Jovanovska, D. Rajchanovska, I. Filov, B. Bogdanova. The relation between psychosocial work factors and musculoskeletal symptoms among computer workers. Internetional conference on innovations in science and education. March 23-25, 2016, Prague, Czech Republic P. 669-675. DOI 10.12955/cbup.v4.830.

5. Наумов А.В., Семенов П.А., Верткин А.Л. Стратегия лечения пациентов с болью и соматической патологией. Consilium Medicum. 2010. T. 12. № 9. С. 111-114.

6. Мазайшвили К.В., Киян К.А., Суханов А.В., Шириязданова Ю.Ф. Распространенность и сочетаемость хронических венозных расстройств нижних конечностей, синдрома беспокойных ног, тревоги и депрессивных состояний среди работников предприятий Московского региона. Флебология. 2019. № 13(1). С. 12-18. DOI 10.17116/flebo20191301112.

7. Сафонова Т.Н. “Сухой глаз” - тут виновник не только компьютер. Энергия: экономика, техника, экология. 2010. № 1. С. 68-70.

8. Maslach C., Schaufeli W.B., Leiter M.P. Job Burnout. Annual Review of Psychology. 2001. № 52. P. 397-422.

9. Herbert J. Freudenberger. Staff Burn-Out. Journal of Social. 1974. Vol. 30, Issue 1. P. 234-242. 
10. Dong S.S., Byung Y.J., Myoung H.P. Structural equation modeling of office environment quality, sick building syndrome, and musculoskeletal complaints on aggregate satisfaction of office workers. Human Factors and Ergonomics in Manufacturing. 2018. Vol. 28 (6), Issue 3. P. 101-162. DOI 10.1002/hfm.20730.

11. Maslach C., Schaufeli W.B., Leiter M.P. Job Burnout. Annual Review of Psychology. 2001. № 52. P. 397-422.

12. Herbert J. Freudenberger. Staff Burn-Out. Journal of Social. 1974. Vol. 30, Issue 1. P. 234-242.

13. Dong S.S., Byung Y.J., Myoung H.P. Structural equation modeling of office environment quality, sick building syndrome, and musculoskeletal complaints on aggregate satisfaction of office workers. Human Factors and Ergonomics in Manufacturing. 2018. Vol. 28 (6), Issue 3. P. 101-162. DOI 10.1002/hfm.20730.

14. Chung-Yen Lu, Meng-Chuan Tsai, Chih-Hsin Muo, Yu-Hsien Kuo, Fung-Chang Sung. Personal, Psychosocial and Environmental Factors Related to Sick Building Syndrome in Official Employees of Taiwan. Int. J. Environ. Res. Public Health. 2018. № 15(1). P. 7-16. DOI 10.3390/ijerph15010007.

15. Chung-Yen Lu, Meng-Chuan Tsai, Chih-Hsin Muo, Yu-Hsien Kuo, Fung-Chang Sung. Personal, Psychosocial and Environmental Factors Related to Sick Building Syndrome in Official Employees of Taiwan. Int. J. Environ. Res. Public Health. 2018. № 15(1). P. 7-16. DOI 10.3390/ijerph15010007.

16. Lu C.Y., Lin J.M., Chen Y.Y., Chen Y.C. Building-Related Symptoms among Office Employees Associated with Indoor Carbon Dioxide and Total Volatile Organic Compounds Building-Related Symptoms among Office Employees Associated with Indoor Carbon Dioxide and Total Volatile Organic Compounds. Int. J. Environ. Res. Public Health. 2015. № 12(6). P. 5833-45. DOI 10.3390/ijerph120605833.

17. Lindo J.L., LaGrenade J., Eldemire-Shearer D. The Health of OfficeBased Workers in Kingston, Jamaica. Workplace Health Saf. 2017. № 65(2). P. 74-82. DOI 10.1177/2165079916667735.

18. Erek K. Helseth, Jay C. Erickson_The Prevalence and Impact of Migraine on US Military [Erek K. Helseth, Jay C. Erickson_The Prevalence and Impact of Migraine on US Military Officer Trainees. Headache. 2008. № 48 (6). P. 883-9. DOI 10.1111/j.1526-4610.2007.00962.x

19. Eltayeb, Shahla Staal, J Bart Khamis, Amar Bie, Rob. (2009). Work Related Risk Factors for Neck, Shoulder and Arms Complaints: A Cohort Study Among Dutch Computer Office Workers. Journal of occupational rehabilitation. 2009. № 19. P. 315-22. DOI 10.1007/s10926-009-9196-x. 
20. Montero-Marín J., García-Campayo J. A newer and broader definition of burnout: Validation of the "Burnout Clinical Subtype Questionnaire (BCSQ-36)”. BMC Public Health. 2010. № 10, p. 302. DOI 10.1186/1471-2458-10-302.

21. Charlson M.E, Pompei P., Ales K.L., McKenzie C.R. A new method of classifying prognostic comorbidity in longitudinal studies : development and validation. J. Chron. Dis. 1987. № 40(5). P. 373-383.

\section{Information about author:}

Savytcka I. B.,

Candidate of Medical Sciences, Associate Professor of the Department of Clinical Neurology, Psychiatry and Narcology

V. N. Karazin Kharkiv National University 4, Svobody Sq., Kharkiv, 61022, Ukraine 